\title{
Praktek Requirement Engineering: Persiapan Implementasi Teknologi QR Code Pada Kegiatan Bimbingan Tugas Akhir
}

\author{
Asep Somantri ${ }^{1, *}$ \\ ${ }^{1}$ Teknik Informatika; Universitas Pasundan; Jl. Dr. Setiabudhi No.193, Kota Bandung, Kode Pos \\ 40153,Telp/Fax 022-2019435/022-2019329; e-mail: somantri@unpas.ac.id \\ * Korespondensi: e-mail: somantri@unpas.ac.id
}

Diterima: 2 Maret 2020; Review: 7 Maret 2020; Disetujui: 13 Maret 2020

Cara sitasi: Somantri A. 2020. Praktek Requirement Engineering: Persiapan Implementasi Teknologi QR Code pada Kegiatan Bimbingan Tugas Akhir. BINA INSANI ICT Journal. Vol.7 (1): 1-12.

\begin{abstract}
Abstrak: Maraknya penggunaan Smartphone sebagai sebuah teknologi yang saat ini dapat digunakan untuk melakukan verifikasi dan validasi pada proses pengesahan data transaksi, hal ini juga telah mendorong perkembangan teknologi agar dapat mendukung proses tersebut. Saat ini, teknologi QR Code telah dimanfaatkan untuk memudahkan penggunanya dalam melakukan proses pengesahan data transaksi (contoh: transaksi jual-beli, kehadiran suatu acara, registrasi pada suatu komunitas, dll.). Penelitian ini bertujuan untuk menunjukkan peluang bahwa teknologi QR Code dapat digunakan untuk verifikasi dan validasi pada proses pencatatan berita acara bimbingan Tugas Akhir (TA) yang terjadi antara Peserta TA dengan Pembimbing TA. Penelitian dilakukan dengan metode Requirement Engineering (RE) untuk memperoleh gambaran tentang kondisi sistem saat ini serta menganalisis data, proses, dan infrastruktur yang diperlukan. Penelitian ini menghasilkan hal-hal yang diperlukan untuk melakukan implementasi teknologi QR Code berupa spesifikasi sistem target yang dapat digunakan untuk menyiapkan organisasi dalam mengimplementasikan teknologi QR Code pada proses pencatatan kehadiran bimbingan TA.
\end{abstract}

Kata kunci: requirement engineering, tugas akhir, teknologi QR code, verifikasi, validasi.

Abstract: The rise of the use of smartphones as a technology that can currently be used to verify and validate the transaction data has encouraged the development of technology to support that process. At present, QR Code technology has been utilized to facilitate its users in the process of validating transaction data (for example: buying and selling transactions, the presence of an event, registration in a community, etc.). This study aims to show the opportunity that $Q R$ Code technology can be used for verification and validation in the process of recording the progress of final thesis activity that occurs between students and advisors. The study was conducted using the Requirement Engineering method to obtain an overview of the current state of the system and analyze the data, processes and infrastructure required. This research produced the system requirements to implement $Q R$ Code technology in the form of a system target specification that can be used to prepare organizations to implement $Q R$ Code technology in the process of recording the progress of final thesis activity.

Keywords: final thesis, $Q R$ code technology, requirement engineering, verification, validation.

\section{Pendahuluan}

Pemanfaatan teknologi QR Code saat ini semakin meluas pada berbagai kegiatan transaksi, contohnya pembayaran digital, presensi kegiatan, registrasi pada suatu grup atau komunitas, dll. Teknologi QR Code juga dapat digunakan untuk verifikasi dan validasi pada proses pengesahan data transaksi secara online dan realtime. Tentunya hal ini sangat membantu para penggunanya, karena memberikan kemudahan saat melakukan transaksi. 
Peluang pemanfaatan teknologi ini masih banyak, dan salah satu peluang penerapan yang ditemukan adalah penerapannya pada Proses Pencatatan Kehadiran Bimbingan Tugas Akhir di Program Studi Teknik Informatika, Fakultas Teknik, Universitas X, Bandung (nama institusi disamarkan).

Tugas Akhir (TA) merupakan salah satu syarat yang harus diselesaikan oleh seorang Mahasiswa agar dapat lulus dan memperoleh gelar Sarjana dari suatu Universitas. Proses penyelesaian TA melibatkan Peserta TA yang mengerjakan penelitian, dan Pembimbing TA yang membimbing Peserta TA dalam melakukan penelitian. Proses pembimbingan TA harus dicatat pada berita acara bimbingan TA. Saat ini, Peserta TA merekamnya melalui media kertas (Form Bimbingan) yang rentan dengan kerusakan dan kehilangan data. Model perekaman tersebut membuat kegiatan bimbingan TA sulit dimonitor secara realtime oleh pihak-pihak yang memerlukan informasi tentang frekuensi pembimbingan TA yang harus dilakukan secara intensif.

Ada banyak penelitian yang dilakukan terhadap QR Code meliputi pemanfaatannya pada Sistem Rumah Sakit [1], Penelusuran Kendaraan [2], dan Aplikasi Robot [3], namun sepanjang hasil pencarian hingga saat penelitian ini dibuat, belum ditemukan penerapannya untuk verifikasi dan validasi pada proses pengesahan data transaksi dalam pencatatan kehadiran bimbingan TA.

\section{Metode Penelitian}

Penelitian ini dilakukan dengan metode pengumpulan data meliputi observasi, wawancara, dan studi literatur. Identifikasi kondisi sistem saat ini, proses analisis persoalan dan analisis kebutuhan sistem dilakukan dengan menggunakan metode Requirement Engineering.

\section{Pengenalan Teknologi QR Code}

QR code atau Quick Response Code adalah kode matriks 2D yang dirancang untuk mempertimbangkan dua hal yaitu adanya penyimpanan data dalam jumlah besar seperti $I D$ barcodes, dan kode sandinya harus dapat dibaca dengan cepat oleh alat (contohnya Handphone). QR Code memiliki kapasitas penyimpanan data yang besar, pemindaian cepat, keterbacaan omnidirectional, dan banyak keuntungan lainnya [4]. Penggunaan $Q R$ code saat ini diterapkan pada berbagai macam aplikasi yang terkait dengan marketing, keamanan, akademik, dll. Kemudian pengunaanya memperoleh popularitas dengan cepat, setiap harinya banyak orang yang mengetahui teknologi ini dan mulai menggunakannya. Pemakaian $Q R$ code tumbuh dengan cepat seiring dengan tumbuhnya penggunaan smartphone [4].

Sistem $Q R$ code terdiri dari $Q R$ code encoder dan decoder. Encoder bertanggungjawab untuk membuat kode data atau sandi, dan decoder membaca sandi data dari $Q R$ code. Teks biasa, URL atau data lain yang diinput ke $Q R$ Code Encoder maka akan di-generate $Q R$ codenya, kemudian saat data $Q R$ code ingin diakses, maka digunakan $Q R$ Code decoder sebagai alat pembacanya, sehingga kode pada $Q R$ code dapat dibaca.

\section{Prosedur untuk Menciptakan dan membaca QR Code}

Sebagaimana dijelaskan pada gambar 2 bahwa $Q R$ code dibuat oleh alat yang bernama $Q R$ Code Encoder. Kita dapat memasukkan tulisan apapun yang kemudian setelah dilakukan proses encode maka akan tercipta $Q R$ Code-nya. $Q R$ code dapat dibaca oleh decoder-nya, sehingga menghasilkan data yang sama dengan data yang diinputkan ke encoder. Berikut adalah alur proses encoding \& decoding.

Proses encoding (gambar 1) menunjukkan tahapan melakukan encode yang dimulai dengan analisis input data yang menerima inputan berupa teks, kemudian proses data encoding menghasilkan bits dari string yang dipecah masing-masing sepanjang 8 bit. Berikutnya setiap karakter dalam string masing-masing dibuat simbol, sehingga muncul $Q R$ code-nya.

Proses decoding (gambar 2) menunjukkan tahapan dalam membaca data dari $Q R$ code yang pada saat dipindai harus menghasilkan teks yang sama seperti yang di-input-kan pada proses encoding. Proses pembacaan dimulai dari mengenali modul yang digunakan untuk membuat kode, kemudian mengekstrak dan menetapkan format informasi yang akan dibaca, jika ditemukan error, maka akan dilakukan koreksi, jika tidak, maka kode akan langsung ditampilkan. 


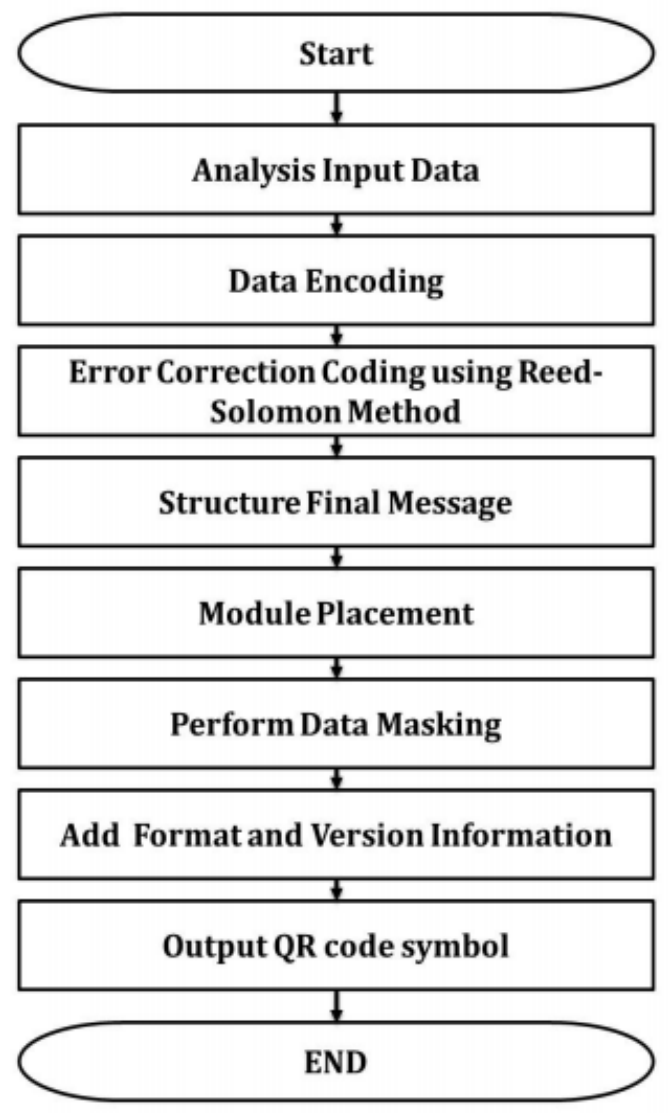

Sumber: Tiwari S., 2016

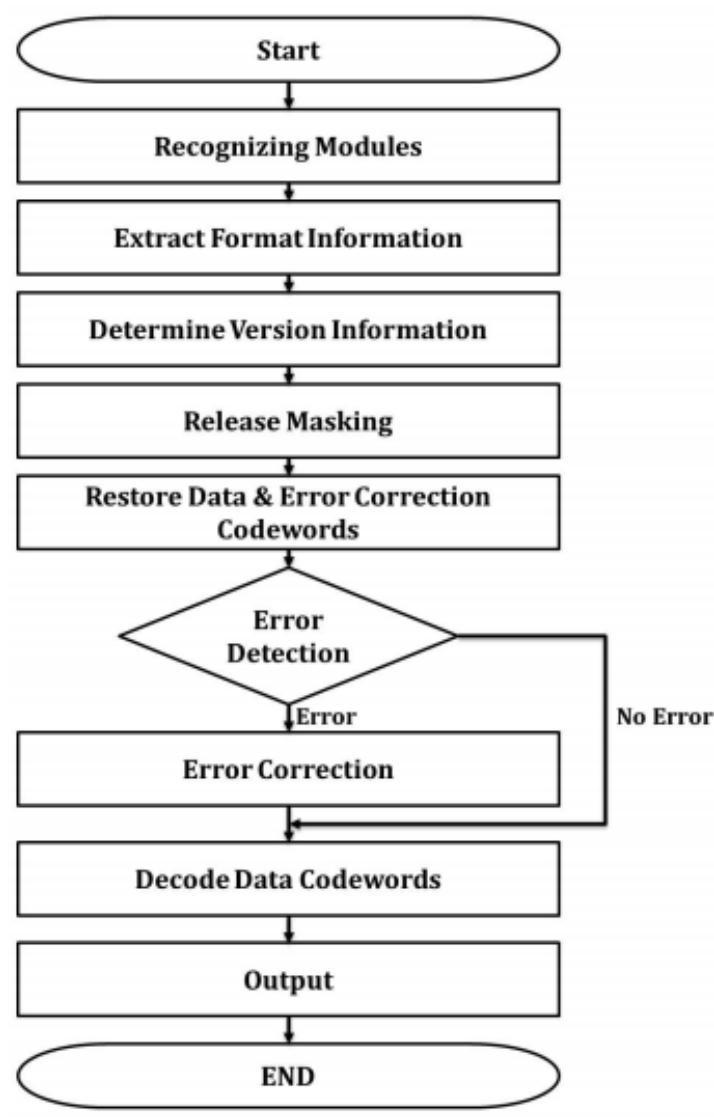

Sumber: Tiwari S., 2016.

Gambar 2 Proses Decoding

\section{Verifikasi dan Validasi}

Verifikasi adalah membandingkan serangkaian aktivitas terpisah antara proses yang diperiksa dan proses pemeriksaan agar dapat memastikan apakah proses yang diperiksa memang dilakukan [5]. Kemudian, Validasi dijalankan untuk menjamin bahwa prosesnya memang benar dilakukan [5]. Terkait dengan kasus pada penelitian ini, proses yang dimaksud tersebut adalah proses bimbingan Tugas Akhir. Menurut kamus besar bahasa Indonesia, verifikasi adalah pemeriksaan tentang kebenaran sebuah laporan, dan validasi adalah memastikan bahwa sebuah proses dilakukan sebagaimana mestinya [6]. Dapat disimpulkan bahwa verifikasi adalah proses pemeriksaan dan validasi adalah pembuktian.

\section{Tugas Akhir (TA)}

Tugas Akhir (TA) adalah karya tulis ilmiah mahasiswa dengan kegiatan penelitian atau desain yang orisinal dan terbimbing oleh Dosen Pembimbing dengan kualifikasi yang relevan. Dengan mengerjakan Tugas Akhir diharapkan mahasiswa mampu menganalisis dan mengidentifikasi persoalan, serta mampu bekerja secara sistematis, logis, kreatif, kritis, orisinal dan berbobot [7]. Dengan menyusun TA diharapkan mahasiswa mampu merangkum, mengaplikasikan, menuangkan, memecahkan semua pengetahuan, keterampilan, ide dan masalah dalam bidang keahlian tertentu secara sistematis, logis, kritis dan kreatif, didukung data/informasi yang akurat dengan analisis yang tepat [7].

\section{Bentuk Tugas Akhir}

Bentuk tugas akhir bisa berupa penelitian atau perancangan, yang terdiri atas proposal tugas akhir dan laporan tugas akhir [7]. Tugas akhir yang berupa penelitian harus mengandung 
kejelasan tentang hal-hal yang ingin diselidiki (something to be inquired or examined) [7]. Sedangkan Tugas akhir yang berupa perancangan harus mengandung kejelasan tentang halhal yang akan dirancang [7],

\section{Prosedur Pelaksanaan Bimbingan Tugas Akhir}

Pelaksanaan bimbingan tugas akhir terjadi antara Pembimbing TA dengan Peserta TA yang diawali dengan kesepakatan waktu/jadwal bimbingan, kemudian dilanjutkan dengan diskusi mengenai topik bahasan atau progress pengerjaan tugas akhir yang dikerjakan oleh Mahasiswa dan diberikan saran atau masukan oleh pembimbing TA. Setelah proses bimbingan selesai maka Mahasiswa mencatat berita acara bimbingan TA pada formulir bimbingan, kemudian disahkan oleh pembimbing dengan menuliskan paraf pembimbing, dan proses terakhirnya adalah Mahasiswa menginputkan berita acara bimbingan ke portal TA (http://ta.ifunpas.org).

\section{Requirement Engineering}

Requirement adalah kondisi atau kapabilitas yang diperlukan oleh user untuk menyelesaikan masalahnya atau mencapai sasaran yang diinginkannya [8]. Penelitian ini menggunakan metode Requirement Engineering yang menekankan pada dimensi proses, budaya, dan teknologi meliputi stakeholders, value, requirements, processes, architecture, validation, integration, dan continuity [9].

\section{Hasil dan Pembahasan}

Berdasarkan tahapan pelaksanaan bimbingan yang dijelaskan pada bagian 2.4.2, persoalan yang seringkali ditemukan adalah pada proses pengisian berita acara ke form bimbingan, dan pemindahan datanya ke portal TA. Beberapa kasus sempat ditemukan seperti rusak/hilangnya form bimbingan, dan form bimbingan telah ditandatangani pembimbing dengan berita yang masih kosong. Adapun data yang sudah terisi pada formulir, seringkali diinputkan pada portal TA menjelang seminar/sidang, sehingga tidak dapat dimonitor secara realtime, mengenai siapa saja yang rajin bimbingan dan siapa saja yang bimbingannya masih kurang. Oleh karena itu, penggunaan teknologi $Q R$ Code penting untuk dilakukan dengan mekanisme sebagaimana diterangkan pada gambar 4 .

\section{Stakeholders}

Semua pemangku kepentingan meliputi pihak yang berinteraksi secara langsung dengan sistem, dan pihak yang terdampak oleh keputusan, aktivitas dan hasil dari sistem [9]. Gambar 3 menunjukkan beberapa pihak yang menjadi Stakeholder dari sistem pencatatan berita acara kehadiran bimbingan TA.

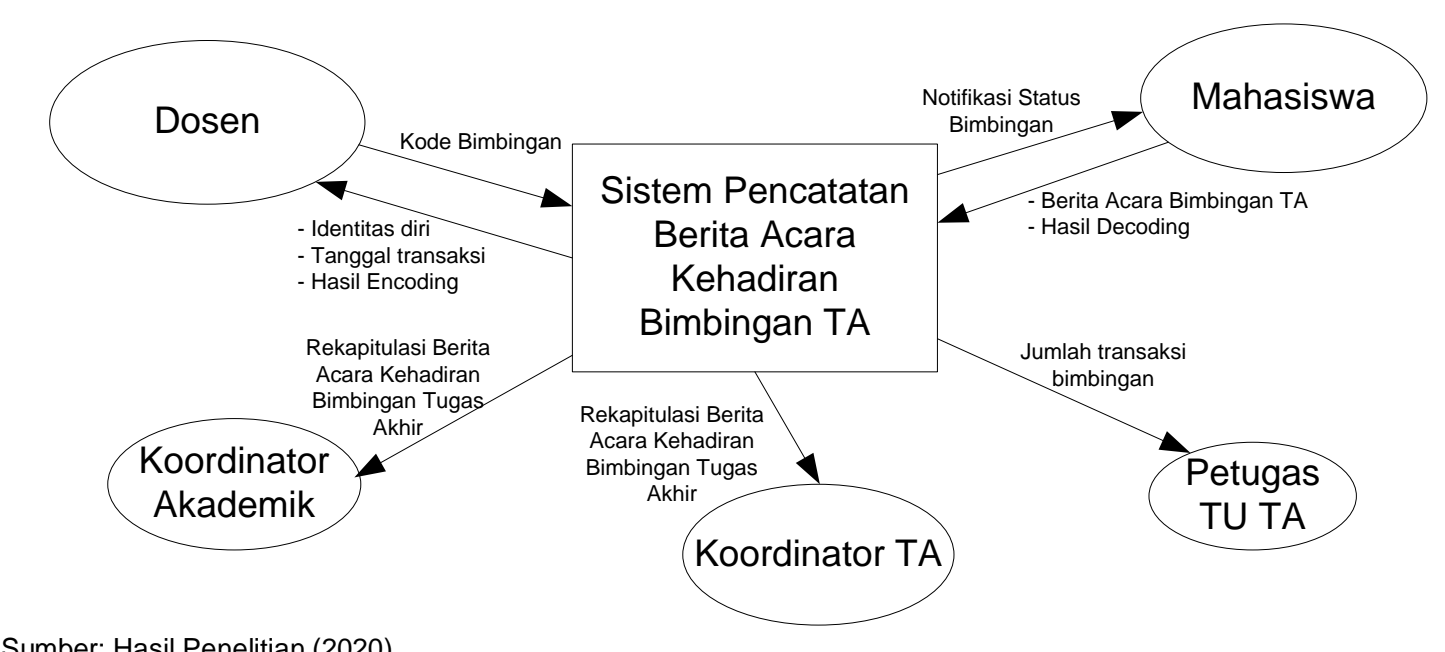

Sumber: Hasil Penelitian (2020)

Gambar 3 Lingkup Sistem 
Aktor yang berinteraksi langsung dengan sistem adalah yang terlibat pada kegiatan tersebut yaitu Mahasiswa (peserta TA), Dosen Pembimbing TA, dan Staff TU TA. Adapun pihak yang terdampak dari sistem adalah Koordinator TA dan Koordinator Akademik. Koordinator TA melakukan pengesahan terhadap pengajuan pelaksanaan Seminar dan Sidang TA, setelah semua persyaratan yang diajukan oleh Mahasiswa sudah lengkap dan benar, yang mana salah satu dari persyaratan tersebut adalah jumlah kehadiran bimbingan. Koordinator Akademik memiliki kepentingan untuk melakukan pengawasan dan evaluasi terhadap rajin atau tidaknya Mahasiswa dalam melakukan bimbingan TA. Koordinator Akademik berkepentingan untuk memberikan penanganan khusus terhadap Mahasiswa yang terlalu lama dalam menyelesaikan TA.

\section{Value}

Kebutuhan user, dan penciptaan value harus dimunculkan berulang-ulang untuk memunculkan pengetahuan implisit, kebutuhan user dan dasar pemikiran bisnis. Requirement dari bisnis harus di-sinkron-kan dengan sasaran bisnis organisasi secara terus menerus [9].

Berdasarkan tahapan pelaksanaan bimbingan, persoalan yang seringkali ditemukan adalah pada proses pengisian berita acara ke form bimbingan, dan pemindahan datanya ke portal TA. Beberapa kasus sempat ditemukan seperti rusak/hilangnya form bimbingan, form bimbingan telah ditandatangani pembimbing dengan berita yang masih kosong. Adapun data yang sudah terisi pada formulir, seringkali diinputkan pada portal TA menjelang seminar/sidang, sehingga tidak dapat dimonitor secara realtime mengenai siapa saja yang rajin bimbingan dan siapa saja yang bimbingannya masih kurang. Oleh karena itu, penggunaan teknologi $Q R$ Code dengan mekanisme sebagaimana diterangkan pada Gambar 4 penting untuk dilakukan. Jika teknologi $Q R$ Code digunakan, maka pencatatan berita acara bimbingan ke portal TA dapat dilakukan secara realtime, sehingga Koordinator Akademik dan Koordinator TA dapat melakukan monitoring terhadap pelaksanaan bimbingan TA secara realtime. Selain itu, data lebih terjaga dari kehilangan, kerusakan, dan ketidaklengkapan.

\section{Requirements}

Keterkaitan antar fungsi harus diidentifikasi sebaik mungkin untuk memenuhi kebutuhan interaksi dan user experience [9]. Gambar 4 mengilustrasikan interaksi yang terjadi antara seorang user dengan user lainnya melalui perantara teknologi, kemudian tabel 2 menunjukkan rancangan interface-nya.
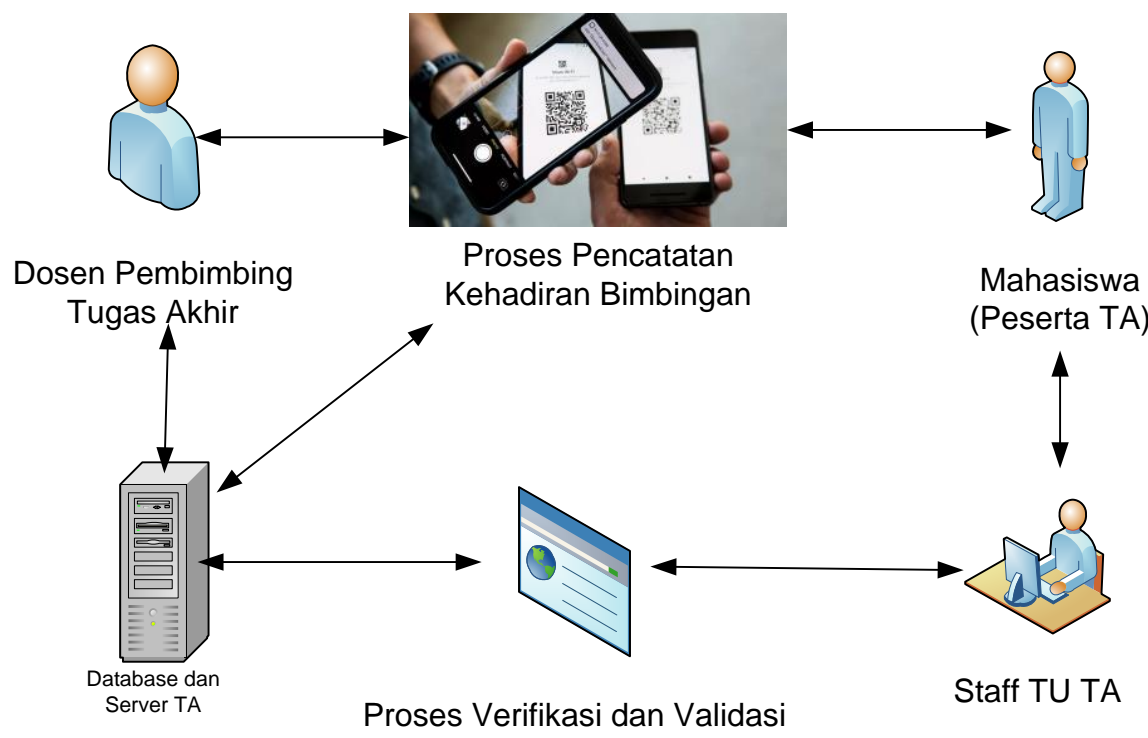

Sumber: Hasil Penelitian (2020)

Gambar 4 llustrasi verifikasi dan validasi kehadiran Mahasiswa pada bimbingan TA

Berdasarkan lingkup sistem yang terdapat pada gambar 3, dan ilustrasi yang terdapat pada gambar 4 menunjukkan bahwa interaksi terjadi antar user dengan menggunakan bantuan 
teknologi, yang artinya user itu sendiri berinteraksi juga dengan teknologi, sehingga ditetapkan kebutuhan sebagai berikut:

Objektif sistem

Sistem mampu melayani Dosen dalam melakukan proses encoding yang bertujuan untuk membuat kode QR pada smartphone miliknya. Kode QR dibentuk dari data Dosen Pembimbing dan data sistem tanggal saat dilaksanakannya bimbingan TA. Sistem mampu memberikan layanan decoding kepada Peserta TA untuk membaca kode QR dari smartphone Dosen pembimbingnya. Jika pemindaian kode dinyatakan valid, dan isian datanya sudah lengkap, maka data berita acara bimbingan TA tersebut dapat tercatat pada database. Sistem mampu memberikan pelayanan monitoring kegiatan bimbingan TA bagi Koordinator TA dan Koordinator Akademik. Sistem mampu melayani Staff TU TA dalam melakukan proses verifikasi dan validasi kelengkapan administrasi berita acara bimbingan para peserta TA Ketersebaran sistem

Data dibuat secara terpusat meliputi pengaksesan data Dosen, pengaksesan data Peserta TA, dan pencatatan berita acara bimbingan TA. Proses pencatatan berita acara bimbingan TA dapat dilakukan secara tersebar, yaitu proses bimbingan TA dapat dilakukan oleh Peserta TA dengan pembimbing utama dan/atau pembimbing pendamping, Layanan bimbingan TA ditetapkan Local Otonom, yaitu layanan pembimbingan hanya dapat dilakukan di kampus

Lingkup sistem ditunjukkan oleh gambar 5. Lingkup sistem dibuat untuk menetapkan posisi sistem pada lingkungannya. Lingkup sistem dibuat dengan menggunakan diagram konteks. Pemodelan lingkup sistem mencantumkan adanya Stakeholders yang memiliki peran terhadap sistem, yaitu memberikan masukkan kepada sistem, lalu menerima feedback-nya. Peran tersebut tercantum dalam tabel 1.

Table 1 Peran Stakeholder

\begin{tabular}{ll}
\hline \multicolumn{1}{c}{ Stakeholder } & \multicolumn{1}{c}{ Deskripsi Peran } \\
\hline Mahasiswa & $\begin{array}{l}\text { Mahasiswa memberikan input hasil decoding dan berita acara bimbingan, kemudian } \\
\text { menerima informasi tentang status bimbingan TA-nya }\end{array}$ \\
\hline Dosen & $\begin{array}{l}\text { Dosen meminta pola gambar hasil encoding untuk di-scan oleh Mahasiswa, kemudian } \\
\text { menerima notifikasi hasil bimbingan }\end{array}$ \\
\hline Petugas TU TA & $\begin{array}{l}\text { Petugas TU TA menerima informasi tentang jumlah bimbingan TA Mahasiswa yang } \\
\text { digunakan untuk pemeriksaan kelengkapan administrasi }\end{array}$ \\
\hline Koordinator TA & $\begin{array}{l}\text { Koordinator TA dan Koordinator Akademik menerima rekapitulasi berita acara } \\
\text { kehadiran Bimbingan TA untuk kepentingan monitoring dan evaluasi }\end{array}$ \\
\cline { 1 - 2 } Koordinator Akademik &
\end{tabular}

\section{Processes}

Alur kerja, layanan, kebutuhan konektifitas, dan tugas pengguna harus dibuat dengan benar, dalam rangka menunjukkan bahwa sistem dapat membantu pengguna untuk menyelesaikan tugas-tugas dan mencapai sasaran-sasarannya [9].

Gambar 5 merupakan rancangan proses untuk sistem target. Proses tersebut dirancang untuk menunjukkan alur kerja, tatacara melayani, memenuhi kebutuhan konektifitas, dan menetapkan proses untuk melayani setiap stakeholder, sehingga rancangan proses ini menunjukkan bahwa sistem dapat membantu pengguna untuk menyelesaikan tugas-tugas dan mencapai sasaran-sasarannya.

Sistem terdiri dari 3 proses utama, yaitu Encoding $Q R$ Code (Proses 1) dilakukan oleh Dosen untuk men-generate gambar $Q R$ Code yamg diperoleh dari data kode Dosen dan tanggal terjadinya bimbingan, lalu proses Decoding $Q R$ Code (Proses 2) dilakukan oleh Mahasiswa dengan memanfaatkan kamera pada Smartphone untuk memindai gambar $Q R$ Code yang ada pada Smartphone Dosen, kemudian data berita acara yang diisikan oleh Mahasiswa pada form layar smartphone di-insert ke database. Proses 3 adalah proses untuk menampilkan data bimbingan Mahasiswa untuk Koordinator TA, Koordinator Akademik, dan Petugas TU TA. 


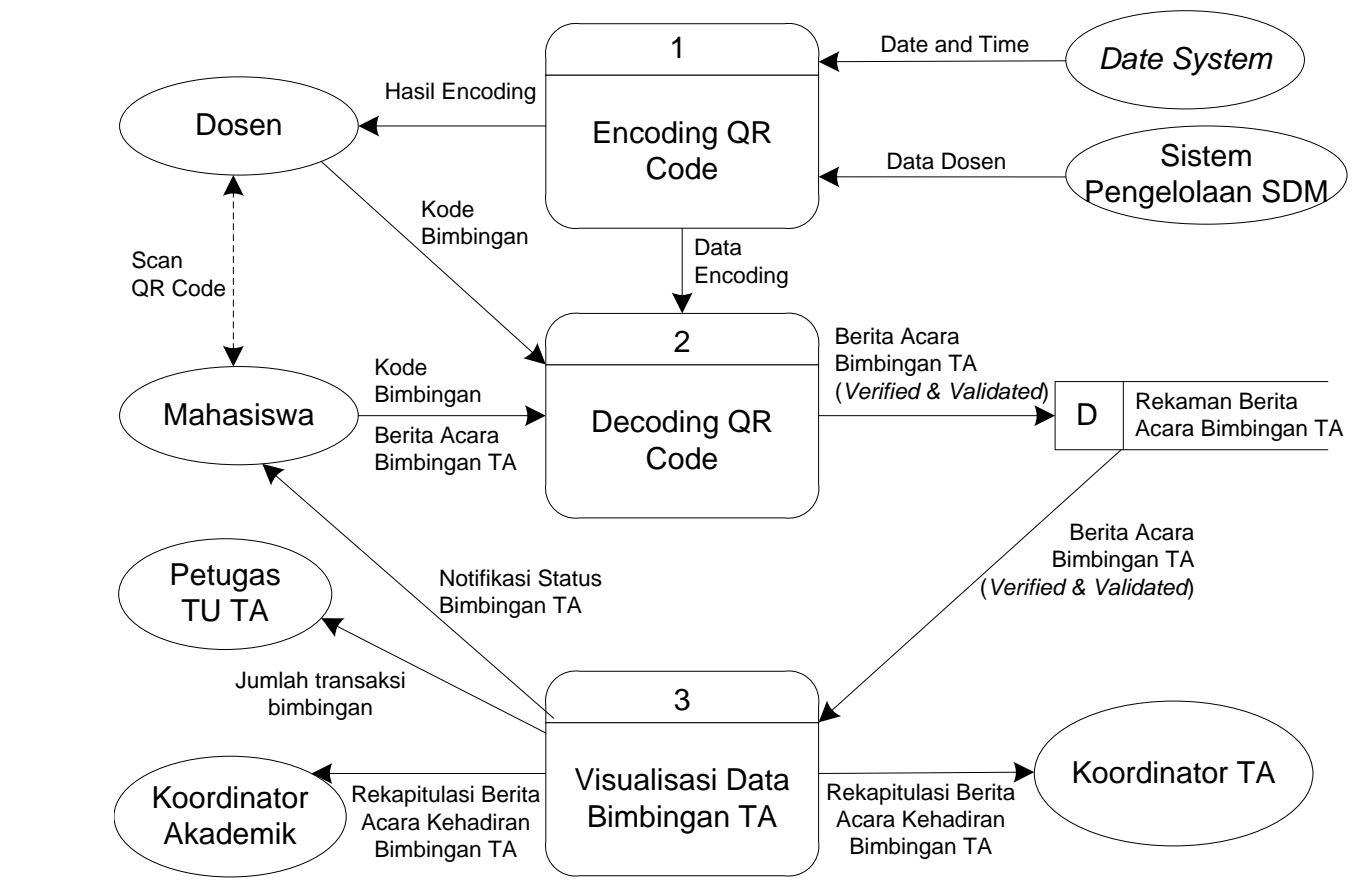

Sumber: Hasil Penelitian (2020)

Gambar 5 Rancangan Proses untuk Sistem Target

\section{Architecture}

Konsistensi setiap objek pada antarmuka harus dapat dijamin dengan komponen software yang reusable. Arsitektur sebuah sistem harus fleksibel, sehingga mampu untuk merespon setiap perubahan dengan baik [9]. Gambar 4 dan 5 menunjukkan bahwa sistem dirancang untuk selalu dapat merespon masukan yang diberikan dan dapat mencegah input data jika terdapat kesalahan dan/atau ketidaklengkapan pada data yang hendak dicatat. Hal ini menyebabkan tidak adanya kemungkinan merespon perubahan permintaan dari user, karena kemungkinan salah input sudah dicegah saat hendak melakukan input data. Hal tersebut disesuaikan dengan prosedur tentang pencatatan berita acara bimbingan TA yang ditetapkan untuk memenuhi kebutuhan organisasi.

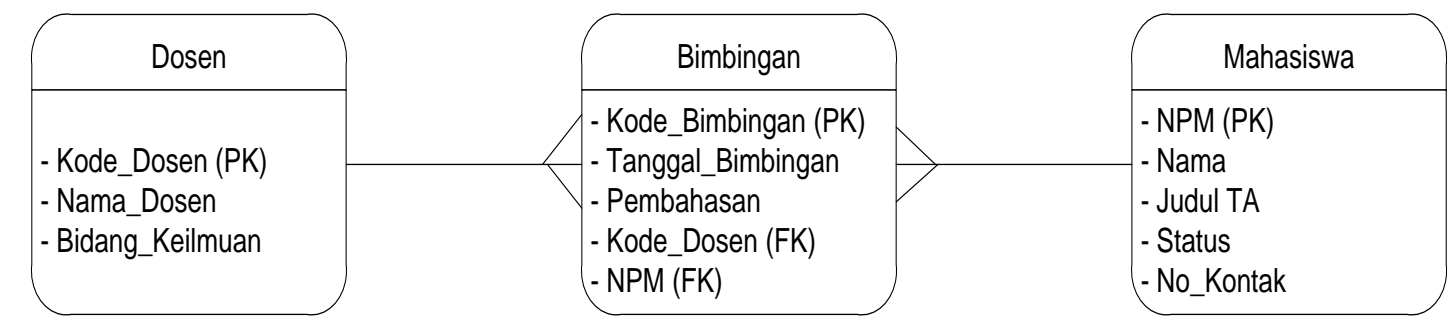

Sumber: Hasil Penelitian (2020)

Gambar 6 Rancangan Data

Rancangan data dibuat untuk memenuhi kebutuhan organisasi dalam melayani Mahasiswa yang hendak mencatat kehadiran dirinya pada bimbingan TA. Dengan merujuk pada gambar 5 dan 6 , data yang dikelola pada sistem ini adalah data Bimbingan, data hasil encoding dan hasil decoding tidak termasuk pada data yang dikelola, karena data hasil encoding adalah data yang terbentuk dari hasil generate Kode_Dosen, NPM dan Tanggal_Bimbingan, lalu terbentuklah kode QR-nya, sedangkan decoding adalah proses (bukan data). 


\section{Validation}

Fungsi dari software harus divalidasi dengan menggunakan simulasi, model dan prototype sesegera mungkin [9]. Tahapan validasi dilakukan dengan membuat rancangan antarmuka. Konsep yang digunakan adalah medium-fidelity wireframe, yaitu suatu rancangan antarmuka yang dibuat dengan menampilkan setiap komponen yang diperlukan untuk menetapkan kebutuhan user [10].

Table 2 Rancangan Antarmuka

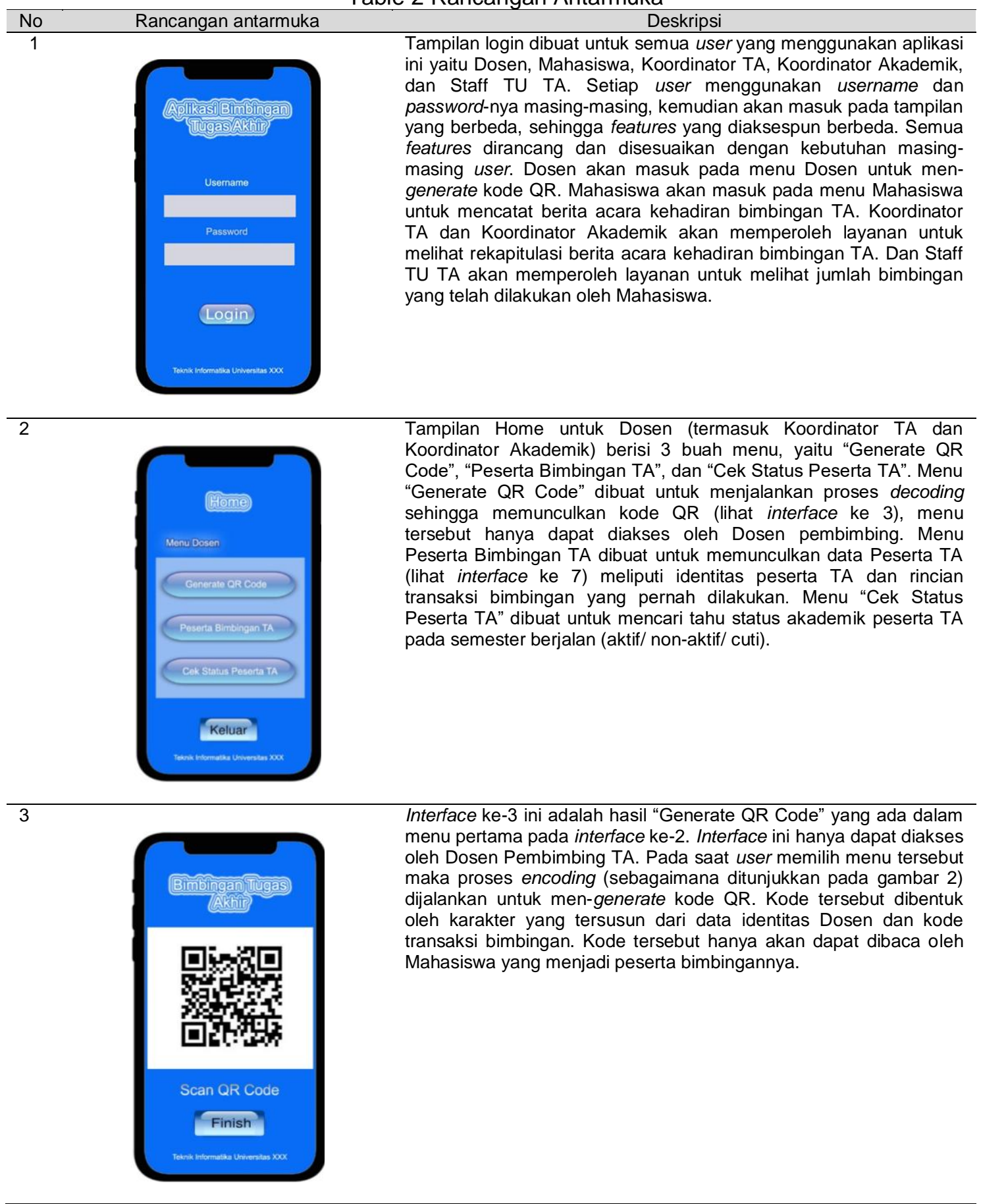


BINA INSANI ICT JOURNAL ISSN: 2355-3421 (Print) ISSN: 2527-9777 (Online); 1 - 12

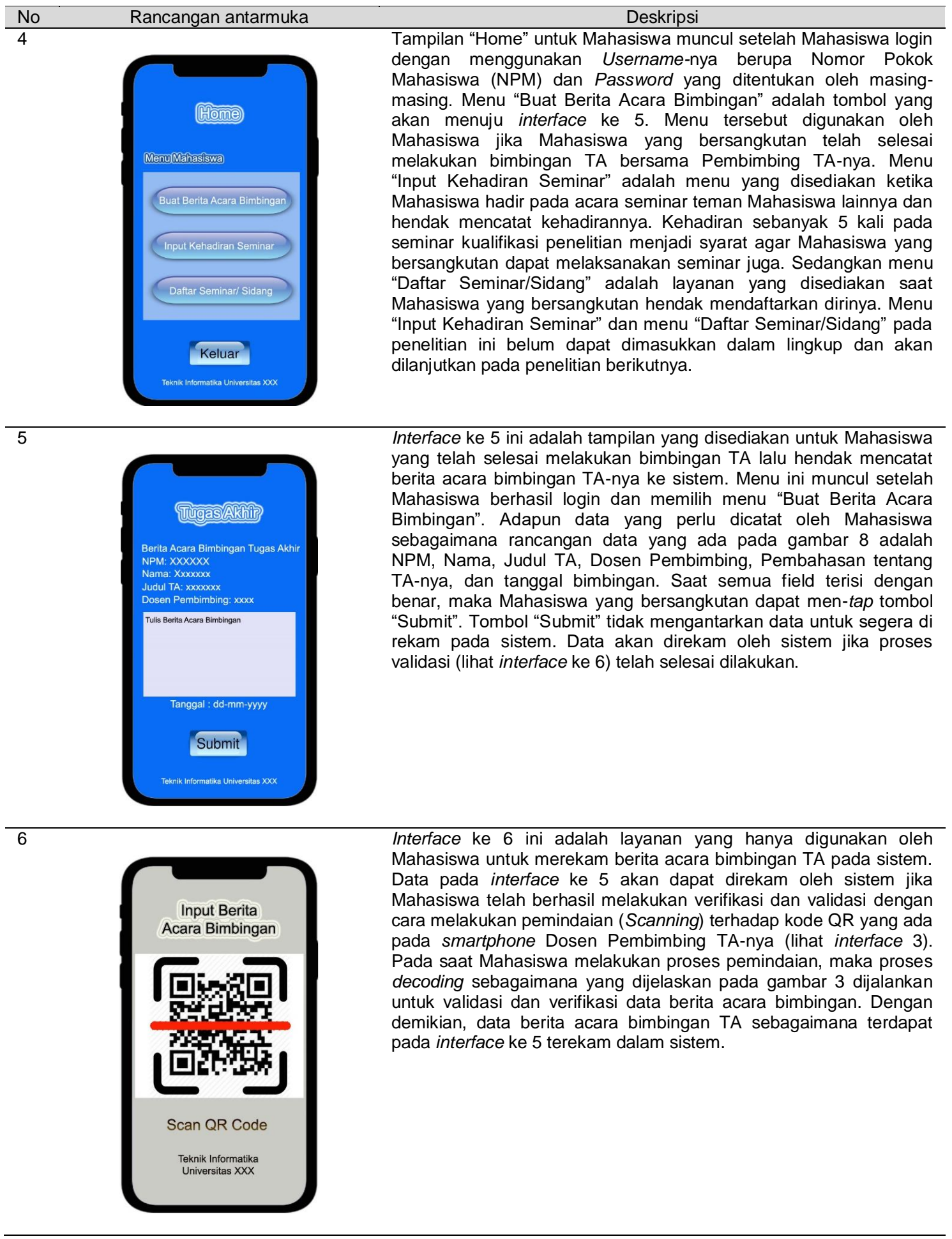




\begin{tabular}{ll}
\hline No & \multicolumn{1}{c}{ Deskripsi } \\
\hline 7 & Rekancangan antarmuka kehadiran bimbingan TA (interface ke 7) ini adalah \\
layanan yang disediakan bagi Dosen, Koordinator TA, dan \\
Koordinator Akademik untuk melihat daftar Mahasiswa yang aktif, \\
kurang, atau bahkan belum bimbingan sama sekali. Interface ini \\
dapat diakses setelah user berhasil login dan memilih menu \\
"Peserta Bimbingan TA" (lihat interface ke 2). Jika login sebagai \\
Dosen Pembimbing, maka hanya daftar Mahasiswa bimbingannya \\
saja yang dapat dilihat. Kemudian jika login sebagai Koordinator TA \\
atau Koordinator Akademik, maka data bimbingan seluruh Peserta \\
TA yang dapat dilihat. Data pada interface ini dapat digunakan untuk \\
melakukan pemantauan terhadap rajin atau tidaknya Mahasiswa \\
dalam melakukan bimbingan. Dosen dapat melihat nomor kontak \\
Mahasiswa untuk keterangan lebih lanjut, sedangkan Koordinator \\
Akademik dapat menetapkan treatment khusus terhadap Mahasiswa \\
yang memasuki Akhir Masa Studi (AMS). Koordinator TA dapat \\
menilai produktivitas Dosen dalam membimbing dengan melihat \\
banyaknya jumlah peserta bimbingan yang telah selesai dan belum.
\end{tabular}

Sumber: Hasil Penelitian (2020)

\section{Integration}

Penjelasan tentang integration meliputi faktor usability dan faktor manusia adalah aspek yang terintegrasi pada metode rekayasa perangkat lunak [9]. User yang terlibat pada sistem pencatatan berita acara kehadiran bimbingan Tugas Akhir adalah Mahasiswa (peserta TA), Dosen Pembimbing TA, dan Staff TU TA. Dalam gambar 4 dan gambar 5 dapat disampaikan bahwa interaksi yang terjadi dalam proses pencatatan kehadiran bimbingan, proses verifikasi dan validasi semuanya dilakukan secara elektronik dan disimpan di basisdata digital. Nielsen, 2010 mendefinisikan usability dengan 5 dimensi dasar, yaitu learnability, efficiency, memorability, error tolerance and prevention, dan satisfaction [11]. Penilaian usability idealnya dilakukan setelah perangkat lunaknya jadi dan telah digunakan oleh user, sehingga user dapat dimintai penilaiannya terhadap perangkat lunak yang digunakannya. Rancangan antarmuka yang terdapat pada tabel 2 telah dibuat dan memang diupayakan untuk memenuhi 5 dimensi dasar tersebut, tetapi hanya didasarkan kepada pengalaman peneliti dalam menganalisis, membangun, dan mengembangkan sistem perangkat lunak serta menilai usability-nya, sehingga penilaian usability untuk rancangan antarmuka ini (lihat tabel 2) belum dapat dilakukan.

Ilustrasi dari sistem verifikasi dan validasi kehadiran Mahasiswa pada bimbingan tugas akhir yang dibutuhkan meliputi beberapa komponen yang saling terhubung. Komponen tersebut antara lain (lihat gambar 4):

Aktor : para pelaku kegiatan, Perangkat Lunak: Aplikasi dari teknologi $Q R$ Code, Perangkat Keras : Mediator untuk proses layanan dan interaksi, Roles : ketetapan terkait aturan dan kebijakan untuk setiap kegiatan pengelolaan, Informasi : feedback bagi pengambil keputusan 


\section{Continuity}

Continuity adalah Keberlanjutan bisnis dan mitigasi risiko seperti perubahan kebutuhan bisnis harus dapat diantisipasi dan diimplementasikan pada infrastruktur IT yang ada saat ini [9]. Pada saat ini setiap Dosen, Mahasiswa, dan Staff dianggap memiliki smartphone. Smartphone adalah perangkat yang diperlukan untuk menerapkan teknologi $Q R$ Code, artinya secara individu setiap user telah memiliki perangkat yang siap untuk menggunakan teknologi QR Code.

Gambar 4 menunjukkan bahwa interaksi yang terjadi dalam proses pencatatan kehadiran bimbingan, proses verifikasi dan validasi semuanya dilakukan secara elektronik dan disimpan di basisdata digital. Staff TU TA melakukan verifikasi dan validasi untuk menentukan lengkap atau tidaknya persyaratan, jika lengkap maka jadwal seminar atau sidang dialokasikan pada jadwal yang berikutnya akan disahkan oleh Koordinator TA. Kegiatan yang perlu dilibatkan dalam sistem ini adalah menggunakan generator $Q R$ Code, membuat program pembaca $Q R$ Code, mengintegrasikan program pembaca $Q R$ Code dengan database Dosen pembimbing dan database Mahasiswa peserta TA, menerapkan komponen validasi dan verifikasi pada program, lalu terakhir simulasi pencatatan kehadiran bimbingan tugas akhir dengan $Q R$ Code

Kesiapan teknologi dan infrastruktur yang ada pada organisasi saat ini telah siap ditunjukkan dengan adanya penerapan berbagai layanan teknologi informasi guna mendukung operasional kegiatan, dimulai dari penggunaan sistem informasi akademik yang terintegrasi, penyimpanan data, layanan telekomunikasi, layanan administrasi, dan layanan hotspot, kemudian jaringan hotspot digunakan sebagai penunjang layanan teknologi informasi, dan pemasangan jaringan hotspot dalam mendukung layanan teknologi informasi melingkupi luas area cakupan hotspot sudah cukup merata ke setiap meja Dosen dan jarang terjadi keluhan pengguna terhadap koneksi yang lambat.

Hasil analisis dari kebutuhan implementasi teknologi $Q R$ Code menunjukkan bahwa fasilitas yang dimiliki oleh organisasi dan setiap user sudah siap dan dapat diandalkan untuk menerapkan teknologi $Q R$ Code, sehingga keberlanjutan penggunaannya akan berjalan dengan baik.

\section{Kesimpulan}

Hasil analisis menunjukkan bahwa pemanfaatan teknologi $Q R$ Code masih terus meluas pada berbagai transaksi. Setelah dilakukannya penelitian ini, dapat ditemukan bahwa pencatatan berita acara bimbingan TA dapat dilakukan dengan memanfaatkan teknologi $Q R$ Code, artinya peluang implementasinya memang sangat bisa. Adapun kesimpulan dihasilkan dari penelitian ini dikelompokkan dalam 3 hal, yaitu kelebihan, kekurangan, dan peluang pengembangan. Kelebihan penelitian ini ditunjukkan dengan lingkup, prosedur, proses, data, interface (antarmuka), dan kesiapan teknologi yang dibutuhkan saat ini sudah jelas teridentifikasi. Kemudian pengembang dapat melakukan pembangunan aplikasi sesuai dengan kebutuhan tersebut, dan daftar kebutuhan yang dibuat untuk sistem target sudah disesuaikan dengan kebutuhan organisasi dan bertujuan untuk memudahkan semua stakeholders dalam menjalankan pekerjaannya. Kekurangan yang berhasil teridentifikasi pada penelitian ini adalah terdapat layanan yang tidak dapat dimasukkan pada lingkup penelitian yaitu layanan registrasi sidang/seminar, dan pencatatan kehadiran seminar. Kemudian kepemilikan perangkat smartphone oleh seluruh user masih berupa anggapan (belum berdasar pada data autentik). Peluang Pengembangan yang dapat dilakukan pada penelitian berikutnya adalah lingkup penelitian dapat dibuat lebih luas meliputi penetapan pembimbing, registrasi seminar/sidang, penjadwalan seminar/sidang, dan pencatatan kehadiran seminar. Penelitian berikutnya dapat dilakukan pada tahap coding yaitu konstruksi perangkat lunak dengan memanfaatkan spesifikasi kebutuhan yang tertera pada penelitian ini.

\section{Referensi}

[1] Uzun V., 2016, QR-Code Based Hospital Systems for Healthcare in Turkey, Annual Computer Software and Applications Conference (COMPSAC), Vol. 2.

[2] Rajesh K., 2018, QR Code-Based Real Time Vehicle Tracking in Indoor Parking Structures, Second International Conference on Intelligent Computing and Control 
Systems (ICICCS).

[3] Çoban M E, et al., 2019, Raspberry Pi Based Robot Application using QR Code: QRRobot, 4th International Conference on Computer Science and Engineering (UBMK).

[4] Tiwari S., 2016, An Introduction To QR Code Technology, International Conference on Information Technology.

[5] Unhelkar B., 2005, Verification and Validation for Quality of UML 2.0 Models. John Wiley \& Sons, Inc. New Jersey.

[6] Setiawan E, 2010, Kamus Besar Bahasa Indonesia.

[7] Majapahit S A. 2015. "Pedoman Tugas Akhir". Prodi Teknik Informatika Unpas. Koord. KP\&TA.

[8] Wundenberg S M., 2015, Requirement Engineering for Knowledge-Intensive Process, Springer Gabler, Laupheim Germany.

[9] Ebert C, 2016, Requirement Engineering for The Digital Transformation, 24 ${ }^{\text {th }}$ International Requirement Engineering Conference.

[10] Still, B. dan Crane, K., 2017, Fundamentals of User-Centered Design - A Practical Approach, Taylor and Francis Group, Boca Raton.

[11] Nielsen J., 2010, Defining Usability, Elsevier, Inc. 